\title{
Evaluation of the Student's Self Awareness, Physical Activity, Sleep Quality, Depression and Life Satisfaction of University Students During the COVID-19
}

\author{
Elif DINLER $^{1}$ (D) Tuğba BADAT ${ }^{2}$, Deniz KOCAMAZ ${ }^{3}$ iD and Yavuz YAKUT ${ }^{4}$ (D) \\ ${ }^{1,2,3,41}$ Department of Physiotherapy and Rehabilitation, Faculty of Health Science, Hasan Kalyoncu University, Gaziantep, \\ Turkey \\ *Corresponding author: deniz.erdankocamaz@hku.edu.tr
}

\begin{abstract}
Background/aim: The aim of this study is to evaluate the levels of self-awareness, physical activity, sleep quality, depression and life satisfaction of university students during the Covid-19 pandemic period. Materials and methods: 200 university students (133 female, and 67 male ) who agreed to participate in the study voluntarily were included. The average age of the students was $21.57 \pm 2.03$. The students replied about the effects of pandemic process with Likert scale that 14 questions. The International Physical Activity Questionnaire (Short Form) (IPAQ-SF), Pittsburgh Sleep Quality Index (PSQI), Beck Depression Scale (BDI), Life Satisfaction Questionnaire (SLWS) were applied to students. Results: According to the results of the study; In the term of Covid-19, it was determined that physical activity and exercise habits were decreased. The participants with good sleep quality. Among the questions in the self-awareness questionnaire, the most frequently participated question by the students was $66 \%$ increase in sitting time and the least agreed $2 \%$ decrease in sitting time. Among these questions, the significance level is $\mathrm{p}=0.01$. Conclusion: During the Covid-19 process, students' self-awareness, physical activity levels, sleep quality and life satisfaction found to be high, and the severity of depression low during the online / distance education period. We think that long-term follow-up studies during the pandemic process will contribute to the literature.
\end{abstract}

Keywords

Covid-19, Physical Activity, Sleep, Depression, Awareness, Distance Education

\section{INTRODUCTION}

Covid-19 infection is a new coronavirus epidemic that first appeared in Wuhan, China at the end of 2019 and has become effective worldwide in a short time (Şencan and Kuzi, 2020). The virus has been identified by the World Health Organization (WHO) as an international public health problem and has been declared to be a pandemic (Mollayeva et al., 2016, İnal İnce et al., 2020 ). With the Covid-19 outbreak, public health measures have emerged to control diseases.
While social isolation and quarantine were recommended at the beginning of the pandemic, with the progress of the process, new normalization studies started all over the world (World Health Organization, 2020).

During the Covid-19 process, some voluntary or involuntary changes occurred in their lives due to the continuation of education in universities with distance education and continuing 
social isolation of students. The pandemic period, which requires the development of self-awareness in particular; students struggle with problems requiring physical effort such as decrease in physical activity level, circadian rhythm sleep problems, and psychological factors (Rastegar Kazerooni et al., 2020).

In a study conducted on students of pharmacy faculty, distance education period positively affected the academic performance of students. (Gossenheimer et al., 2017). Physical activity and exercise increased the quality of life, studies have suggested that it has positive effects on the reduction of depression, development of student's awareness and the related high success rates. In a study involving different exercise modalities and based on physical activity, it was determined that the self-awareness of individuals who received exercise training increased (Patel et al., 2018). It has been shown in studies that physical activity and exercise have positive effects on life quality and depression ( Fisher et al., 2019).

Another important issue on quality of life and health is sleep. Considering the studies on sleep times and sleep quality in university students, it has been observed that there have been significant changes in recent years and the sleep quality of the students has decreased by decreasing their sleep times. Psychological health problems have been observed in individuals with poor sleep quality (Aysan et al., 2014).

During the Covid-19 process, especially in this period, during which the sedentary life is more active, systematic and regular physical activity programs will contribute to the physical and mental change of the person and increase their well-being (Kaya et al., 2018). A high level of physical activity will be extremely effective on sleep quality, depression severity and quality of life, and it is important to develop individual physical activity / exercise programs for this. Exercise programs developed specifically for the individual can be carried out effectively, especially during the social isolation period ( Lee, 2020). In addition, increasing physical activity levels with exercise programs prepared specifically for individuals will enable them to enjoy life more (Tunay, 2008) In addition to the abundance of studies on quality of life, there are not enough studies in the field of physiotherapy in terms of life satisfaction. The fact that social isolation and distance education are experienced around the world, increasing the awareness of students is essential for us to continue their education and training life at home as much as possible. In this context, it will be beneficial in terms of public health to carry out studies that focus on individual exercise programs, increase the physical activity levels of students and increase sleep quality, reduce depression and increase life satisfaction.

In the light of these information, the aim of this study is to evaluate the levels of selfawareness, physical activity, sleep quality, depression and life satisfaction of university during the Covid-19 pandemic process.

\section{MATERIALS AND METHODS}

\subsection{Study design and Ethics approval}

This study is a cross-sectional descriptiveanalytic and survey-based study. All participants were properly informed about the study. Ethics approval was obtained from the Local Ethical Committee (date-decision no: 24/04/20202020/20). The study was conducted in accordance with the principles of the Declaration of Helsinki. All measurements were completed on online platform. The evaluations were administered by authors who are physiotherapist.

\subsection{Participants}

All participants were students in Hasan Kalyoncu University, Faculty of Health Sciences and Department of Physiotherapy and Rehabilitation in Gaziantep. All the data were collected between April and July 2020. Participants were eligible for the study if they (a) were from 18 to 30 years of age, and (b) had no previous history of depression. Participants who underwent had positive diagnosis of Covid and contacting people with Covid were excluded from the study. The risk status of the students was checked by HES application.

For the 266 university students $95 \%$ confidence coefficient, $\alpha=.05$ significance and $5 \%$ tolerance level was calculated as the sample size. Students were invited to participate in the study in 3 different periods. A total of 200 (133 females, 67 male) students voluntarily participated in the study. It was the $75.1 \%$ of the total universe. The Consolidated Standards of Reporting Trials (CONSORT) table which depicts patient flow throughout the study were given on Figure 1. 


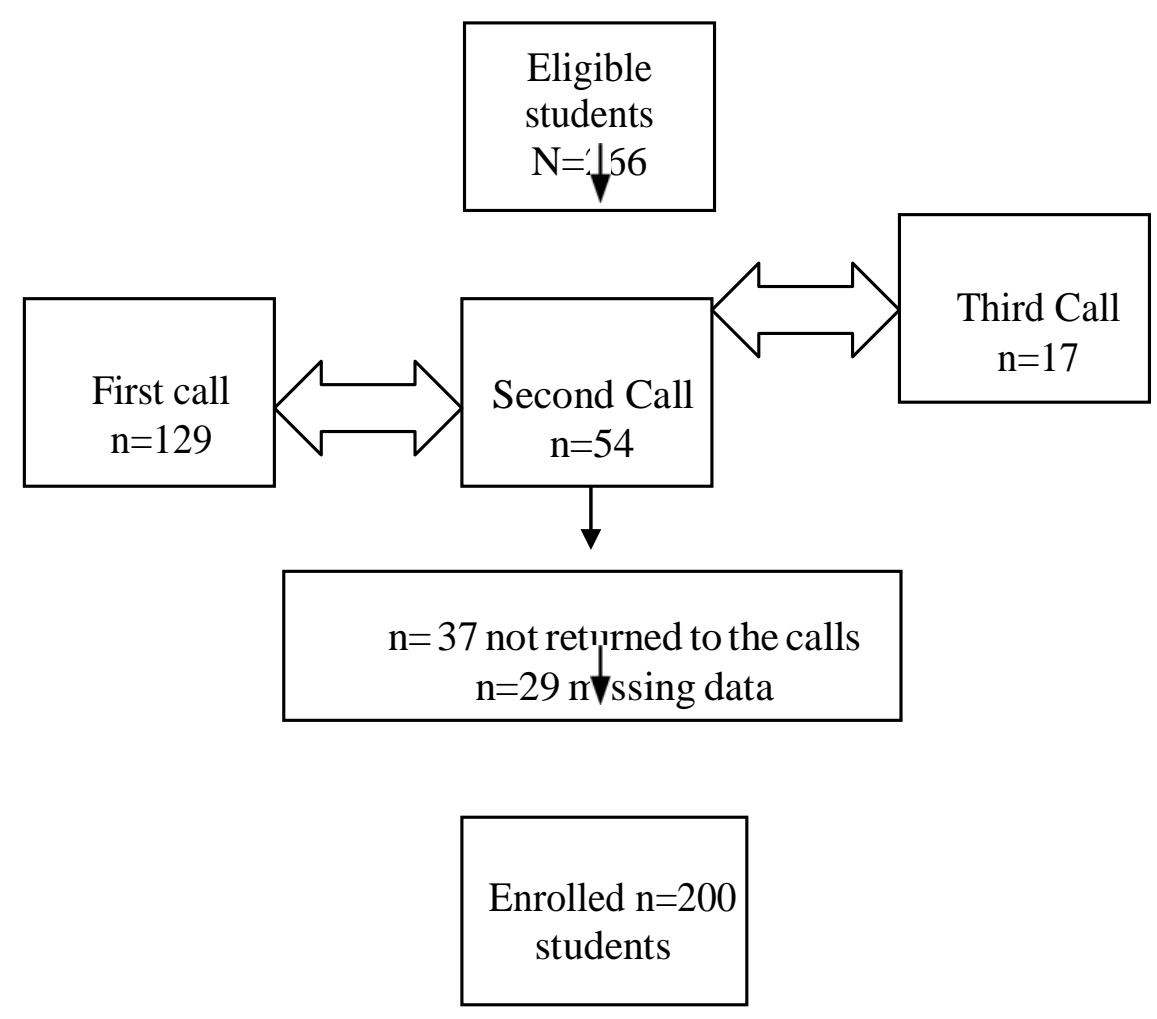

Figure I. Flow Chart For Participants (The Consolidated Standards of Reporting Trials)

Students were asked to be include voluntarily of the study. The participants were motivated as that they have an important contribution to the development of pandemic process and distance education.

\subsection{Evaluation Methods}

The demographic characteristics including age, gender, height, weight were recorded. Patients completed standard and non-standardized instruments. All participants completed standard instruments included that sleep quality (Pittsburgh Sleep Quality Index-PSQI), life satisfaction (Satisfaction With Life Scale-SWLS), physical activity (International Physical Activity Questionnaire-Short Form IPAQ-SF), and depression (Beck Depression Inventory- BDI) questionnaires.

The PSQI is a self-rating questionnaire resulting in a global score between 0 and 21 higher scores indicate worse sleep quality (Mollayeva et al., 2016). The SWLS is a well-known and wellused instrument of the cognitive-judgmental component of subjective well-being. The coefficients alpha of SLWS have ranged from 0.79 to 0.89 (Lorenzo Seva et al., 2019). The IPAQ-SF has been recommended as a cost-effective method to assess physical activity for the last 7 day's report ( Lee et al., 2011). The BDI is a 21-item selfreporting inventory for evaluating the depression in normal and psychiatric populations (Jackson Koku, 2016).

There were 14 questions asked the student with non-standardized instrument. In additionally, 14 questions were asked the student with nonstandardized instrument. It was used to guideline for this study designed for collect data on the views about to the pandemic process on physiotherapy students. Data were obtained by a questionnaire, prepared by the researchers (they have 5-10-35 years of experience on physiotherapy and rehabilitation) according to the literature. The questionnaire was edit and confirmed by a professional department in terms of terminology and expression. Likert type scale was used in 14 questions ( 1 for totally disagree up to 5 for totally agree) which were including completely agree, 
agree, no idea, disagree and completely disagree. The purpose of the study was explained to the to them. It was optional for students to write their identity for the reliability of the feedback.

\subsection{Statistical analysis}

Statistical analysis was performed using Statistical Package for Social Sciences (SPSS Version 22, Armonk, NY: IBM Corp.). The level of statistical significance was set at $\mathrm{p}<0.05$. The variables were investigated by visual (histograms, probability plots) and analytical methods (ShapiroWilk test) to determine whether they were normally distributed. Descriptive statistics were calculated for all variables, and the data were shown as mean \pm standard deviation $(\mathrm{SD} \pm \mathrm{SS})$, median (minimum-maximum), frequencies and percentages. Demographic data of students was compared using Independent sample-test and expressed 95\% confidence interval (CI). Gender difference was compared using Chi-Square Test. Since data (depression, physical activity and sleep quality) were not normally distributed, comparisons were performed using MannWhitney U test. Spearman correlations were calculated to all parameters. The significance level was accepted $p<0.05$.

\section{RESULTS}

$133(66.5 \%)$ female and 67 male $(33.5 \%)$ students participated in this study. The average age of the students was $21.57 \pm 2.03$ (min:19, max: 29).139 ( $69.5 \%$ ) of the students in the participant did not smoke. Students were called in the study in 3 different periods. In the first call, $129(66.5 \%)$ students, in the second call $54(27 \%)$ students and the last call $17(8.5 \%)$ students completed the online form. The term of the students and the place they live in the pandemic process are given in Table 1.

Table 1. The Class Distribution of the Students and the Place They Live in The Pandemic Process.

$$
\text { Frequency (n) Percent }(\%)
$$

\begin{tabular}{lcc}
\hline First Year & 48 & 24 \\
Second Year & 25 & 12.5 \\
Third Year & 68 & 34 \\
Four Year & 59 & 29.5 \\
\hline TOTAL & 200 & 100 \\
\hline Big-city & 147 & 73,5 \\
City & 29 & 14,5 \\
District & 21 & 10,5 \\
Village & 3 & 1,5 \\
\hline TOTAL & 200 & 100 \\
\hline
\end{tabular}

The opinions of the students evaluated the questionnaire that prepared with the Likert scale regarding physical activity and sleep circadian rhythm in the pandemic process. In the results of the questionnaire self awareness of the students were similar in terms of gender. The life satisfaction of the students were high, and not differ by gender during the pandemic process $(p>$ 0.05 ). According to the results of our study, the level of depression (BDI) was higher in women. Sleep quality (PSQI) was found better in men. ( $p$ $<0.05)$ Data on physical activity, sleep quality, 
depression and life satisfaction findings by gender are given in Table 2.

Table 2. The Physical Activity, Sleep Quality, Depression and Life Satisfaction Results of Students.

\begin{tabular}{|c|c|c|c|c|c|c|}
\hline & \multicolumn{2}{|c|}{ Female $(n=133)$} & \multicolumn{2}{|c|}{ Male $(n=67)$} & \multirow[b]{2}{*}{$\mathrm{Z}$} & \multirow[b]{2}{*}{$\mathrm{p}$} \\
\hline & $X$ & $\mathrm{SD}$ & $\mathrm{X}$ & SD & & \\
\hline$\overline{\mathrm{Q} 1}$ & 4,02 & 1,09 & 3,64 & 1,30 & 1,865 & 0,062 \\
\hline$\overline{\mathrm{Q} 2}$ & 4,47 & 0,86 & 4,40 & 0,99 & 0,263 & 0,793 \\
\hline$\overline{\text { Q3 }}$ & 3,78 & 0,97 & 3,72 & 1,04 & 0,406 & 0,685 \\
\hline$\overline{\mathrm{Q} 4}$ & 3,83 & 1,12 & 3,81 & 1,15 & 0,180 & 0,857 \\
\hline$\overline{\mathrm{Q} 5}$ & 3,68 & 0,96 & 3,52 & 1,21 & 0,669 & 0,503 \\
\hline$\overline{\text { Q6 }}$ & 2,34 & 1,15 & 2,30 & 1,30 & 0,534 & 0,593 \\
\hline Q7 & 2,54 & 1,23 & 2,49 & 1,38 & 0,465 & 0,642 \\
\hline$\overline{\mathrm{Q} 8}$ & 1,77 & 0,92 & 1,82 & 1,14 & 0,308 & 0,758 \\
\hline$\overline{\text { Q9 }}$ & 2,75 & 1,26 & 2,66 & 1,44 & 0,618 & 0,537 \\
\hline $\mathrm{Q} 10$ & 2,87 & 1,36 & 2,66 & 1,48 & 1,115 & 0,265 \\
\hline Q11 & 2,71 & 1,30 & 2,70 & 1,41 & 0,129 & 0,897 \\
\hline$\overline{\mathrm{Q} 12}$ & 2,63 & 1,35 & 2,58 & 1,50 & 0,361 & 0,718 \\
\hline$\overline{\mathrm{Q} 13}$ & 2,65 & 1,31 & 2,55 & 1,45 & 0,633 & 0,527 \\
\hline Q14 & 2,57 & 1,42 & 2,39 & 1,47 & 1,053 & 0,292 \\
\hline Total Beck Score & 17,14 & 11,28 & 12,28 & 10,05 & 3,081 & $0,002 *$ \\
\hline Total SWLS Score & 24,62 & 6,84 & 26,36 & 6,45 & 1,812 & 0,070 \\
\hline Total PSQI Score & 8,42 & 3,49 & 7,37 & 3,42 & 2,078 & 0,038 \\
\hline \multicolumn{7}{|l|}{ IPAQ high intensity } \\
\hline exercise & 243,76 & 704,70 & 469,85 & 949,06 & 1,358 & 0,174 \\
\hline IPAQ moderate exercise & 408,04 & 849,79 & 171,40 & 482,29 & 3,145 & $0,002 *$ \\
\hline IPAQ walking & 470,08 & 837,85 & 529,21 & 970,10 & 0,134 & 0,893 \\
\hline IPAQ sitting & 349,17 & 384,09 & 330,45 & 363,86 & 0,055 & 0,956 \\
\hline Total IPAQ & 1471,25 & 1979,26 & 1720,31 & 2669,13 & 0,053 & 0,957 \\
\hline
\end{tabular}

According to the results of the study, a moderate negative correlation was found between life satisfaction and depression (r: - 0.488) and between life satisfaction and sleep quality ( $\mathrm{r}$ : 0.308). A moderate correlation was found between sleep quality and depression (r: 0, 505). A low level relationship was found between physical activity and depression ( $\mathrm{r}$ : 0.025). A low negative correlation was found between physical activity 
and sleep (r: -0.083) and between physical activity and life satisfaction (r: 0.018) (Table 3).

Table 3. The Relationship of Physical Activity Level, Sleep Quality, Depression Level and Life Satisfaction Data of University.

\begin{tabular}{|c|c|c|c|c|c|c|c|c|}
\hline & \multirow{3}{*}{$\begin{array}{c}\text { BDI } \\
\text { Total }\end{array}$} & \multirow{3}{*}{$\begin{array}{c}\text { SWLS } \\
\text { Total }\end{array}$} & \multicolumn{5}{|c|}{ IPAQ } \\
\hline & & & & PSQI & IPAQ high & moderate & IPAQ & IPAQ \\
\hline & & & & Total & intensity & intensity & walking & sitting \\
\hline \multirow[t]{2}{*}{ BDI Total } & $\mathrm{r}$ & - & & & & & & \\
\hline & $\mathrm{p}$ & - & & & & & & \\
\hline \multirow[t]{2}{*}{$\overline{\text { SWLS Total }}$} & $\mathrm{r}$ & $-0,488$ & & & & & & \\
\hline & $\mathrm{p}$ & 0,000 & & & & & & \\
\hline \multirow[t]{2}{*}{ PSQI Total } & $\mathrm{r}$ & 0,505 & $-0,308$ & & & & & \\
\hline & $\mathrm{p}$ & 0,000 & 0,000 & & & & & \\
\hline \multicolumn{9}{|l|}{$\overline{\text { IPAQ high }}$} \\
\hline \multirow[t]{2}{*}{ intensity } & $\mathrm{r}$ & $-0,088$ & 0,142 & $-0,087$ & & & & \\
\hline & $\mathrm{p}$ & 0,214 & 0,045 & 0,218 & & & & \\
\hline \\
\hline moderate & & & & & & & & \\
\hline \multirow[t]{2}{*}{ intensity } & $\mathrm{r}$ & 0,005 & 0,037 & $-0,072$ & 0,275 & & & \\
\hline & $\mathrm{p}$ & 0,947 & 0,604 & 0,312 & 0,000 & & & \\
\hline \multirow[t]{2}{*}{ IPAQ walking } & $\mathrm{r}$ & $-0,016$ & $-0,080$ & $-0,051$ & 0,173 & 0,427 & & \\
\hline & $\mathrm{p}$ & 0,823 & 0,261 & 0,470 & 0,014 & 0,000 & & \\
\hline \multirow[t]{2}{*}{ IPAQ sitting } & $\mathrm{r}$ & 0,236 & $-0,110$ & 0,009 & 0,080 & 0,128 & 0,238 & \\
\hline & $\mathrm{p}$ & 0,001 & 0,120 & 0,899 & 0,260 & 0,070 & 0,001 & \\
\hline \multirow[t]{2}{*}{ IPAQ Total } & $\mathrm{r}$ & 0,025 & $-0,018$ & $-0,083$ & 0,522 & 0,625 & 0,707 & 0,511 \\
\hline & $\mathrm{p}$ & 0,726 & 0,796 & 0,244 & 0,000 & 0,000 & 0,000 & 0,000 \\
\hline
\end{tabular}

Spearman Correlation Test

The responses were scored based on the Likert scale, from 1 to 5 points for "totally disagree" through "totally agree" comments. First and second highest scores were pertained to "Q2- I spent more time sitting during the pandemic." (4.5 \pm 0.9 and $3.89 \pm 1.17$, respectively) and the least score was to "Q6-My physical activity level increased during the pandemic." $(2.33 \pm 1.20)$ which were statistically significant $(\mathrm{p}<0.05)$. The questionnaire items and the students' responses about pandemia process given in Table 4 .

The relationship between the scores of participants for the duplicated control question was calculated by Pearson's product-moment correlation coefficient as $r=0.91, p<0.01$. Thus, it can be said that the participants answered the questionnaire honestly. According to the results of the student' self awareness questionnaire developed within the scope of our study, $48 \%$ of the participants stated that the sitting time in the pandemic period was increased. $26 \%$ of the students thought that their physical activity level increased. While $34 \%$ thought that they spent more time for themselves, $33 \%$ stated that they learned new things (Table 5). 
Table 4. The Questionnaire Items and the Students' Responses About Pandemic Process with Frequencies.

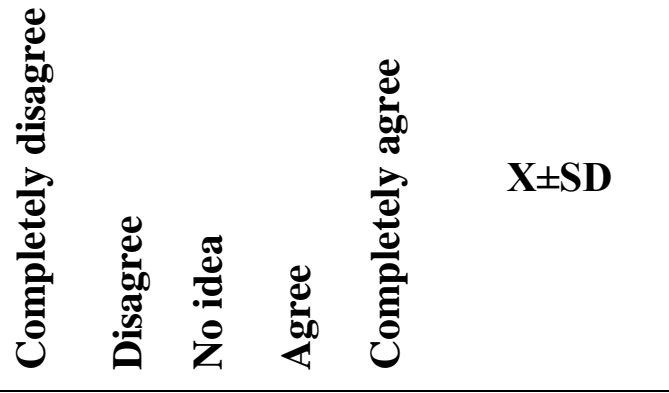

Q1-My sleep pattern was disturbed during the

pandemic.

$\begin{array}{llllll}7 & 21 & 44 & 43 & 85 & 3.89 \pm 1.17\end{array}$

Q2- I spent more time sitting during the pandemic.

$\begin{array}{llllll}3 & 5 & 23 & 38 & 131 & 4.45 \pm 0.90\end{array}$

Q3-I started taking more time for myself during the

pandemic.

$\begin{array}{llllll}5 & 10 & 68 & 62 & 55 & 3.76 \pm 0.99\end{array}$

Q4-I began spending more time with my loved ones

during the pandemic.

$\begin{array}{llllll}8 & 16 & 51 & 53 & 72 & 3.83 \pm 1.13\end{array}$

Q5- I learned new things during the pandemic.

$\begin{array}{llllll}6 & 22 & 59 & 67 & 46 & 3.62 \pm 1.05\end{array}$

Q6-My physical activity level increased during the

pandemic.

$\begin{array}{llllll}63 & 53 & 54 & 16 & 14 & 2.33 \pm 1.20\end{array}$

Q7- The time I spent doing sports increased during the

pandemic.

$\begin{array}{llllll}53 & 53 & 50 & 24 & 20 & 2.52 \pm 1.28\end{array}$

Q8- I spent less time sitting during the pandemic.

$\begin{array}{llllll}104 & 52 & 31 & 9 & 4 & 1.79 \pm 1.00\end{array}$

Q9- I encouraged my family to actively participate in

home exercises during the pandemic.

$\begin{array}{llllll}46 & 46 & 52 & 30 & 26 & 2.72 \pm 1.32\end{array}$

Q10- I enjoyed the time doing exercises with my family

at home.

$\begin{array}{llllll}48 & 43 & 42 & 35 & 32 & 2.80 \pm 1.40\end{array}$

Q11- My parents were enthusiastic about doing home

exercises during the pandemic.

$\begin{array}{llllll}53 & 34 & 54 & 37 & 22 & 2.70 \pm 1.33\end{array}$

Q12- I encouraged my parents to do breathing exercises

at home during the pandemic

$\begin{array}{llllll}64 & 32 & 44 & 37 & 23 & 2.61 \pm 1.40\end{array}$

Q13-.I had my parents to do relaxation exercises during

the pandemic.

57

$\begin{array}{lllll}43 & 42 & 36 & 22 & 2.61 \pm 1.36\end{array}$

Q14- I had my parents to do aerobic exercise (e.g. 
Table 5. Response Percentages According to the Form Prepared with Likert Scale.

\begin{tabular}{|c|c|c|c|c|c|c|c|c|c|}
\hline \multicolumn{2}{|c|}{$\begin{array}{l}\text { Completely } \\
\text { disagree }\end{array}$} & \multicolumn{2}{|c|}{ Disagree } & \multicolumn{2}{|c|}{ No idea } & \multicolumn{2}{|c|}{ Agree } & \multicolumn{2}{|c|}{ Completely Agree } \\
\hline Item & $\begin{array}{l}\text { Frequency } \\
(\%)\end{array}$ & Item & $\begin{array}{l}\text { Frequency } \\
(\%)\end{array}$ & Item & $\begin{array}{l}\text { Frequency } \\
(\%)\end{array}$ & Item & $\begin{array}{l}\text { Frequency } \\
(\%)\end{array}$ & Item & $\begin{array}{l}\text { Frequency } \\
(\%)\end{array}$ \\
\hline Q-08 & $104(52)$ & Q-06 & $53(26.5)$ & Q-03 & $68(34)$ & P05 & $67(33.5)$ & $\mathrm{P} 02$ & $131(66.5)$ \\
\hline Q-14 & $71(35.5)$ & Q-07 & $53(26.5)$ & Q-05 & $59(29.5)$ & $\mathrm{P} 03$ & $62(31)$ & $\mathrm{P} 01$ & $85(42.5)$ \\
\hline Q-12 & $64(32)$ & Q-08 & $52(26)$ & Q-06 & $54(27)$ & $\mathrm{P} 04$ & $53(26.5)$ & $\mathrm{P} 04$ & $72(36)$ \\
\hline Q-06 & $63(31.5)$ & Q-09 & $46(23)$ & Q-11 & $54(27)$ & $\mathrm{P} 01$ & $43(21.5)$ & $\mathrm{P} 03$ & $55(27.5)$ \\
\hline Q-13 & $57(28.5)$ & Q-10 & $43(21.5)$ & Q-09 & $52(26)$ & $\mathrm{P} 02$ & $38(19)$ & $\mathrm{P} 05$ & $46(23)$ \\
\hline Q-07 & $53(26.5)$ & Q-11 & $43(21.5)$ & Q-04 & $51(25.5)$ & $\mathrm{P} 11$ & $37(18.5)$ & $\mathrm{P} 10$ & $32(16)$ \\
\hline Q-11 & $53(26.5)$ & Q-12 & $38(19)$ & Q-07 & $50(25)$ & $\mathrm{P} 12$ & $37(18.5)$ & $\mathrm{P} 14$ & $27(13.5)$ \\
\hline Q-10 & $48(24)$ & Q-13 & $34(17)$ & Q-01 & $44(22)$ & $\mathrm{P} 13$ & $36(18)$ & P09 & $26(13)$ \\
\hline Q-09 & $46(23)$ & Q-14 & $32(16)$ & Q-12 & $44(22)$ & $\mathrm{P} 10$ & $35(17.5)$ & $\mathrm{P} 12$ & $23(11.5)$ \\
\hline Q-04 & $8(4)$ & Q-15 & $22(11)$ & Q-10 & $42(21)$ & P09 & $30(15)$ & $\mathrm{P} 11$ & $22(11)$ \\
\hline Q-01 & $7(3.5)$ & Q-16 & $21(10.5)$ & Q-13 & $42(21)$ & P14 & $28(14)$ & P13 & $22(11)$ \\
\hline Q-05 & $6(3)$ & Q-17 & $16(8)$ & P14 & $36(18)$ & P07 & $24(12)$ & P07 & $20(10)$ \\
\hline Q-03 & $5(2.5)$ & Q-18 & $10(5)$ & P08 & $31(15.5)$ & P06 & $16(8)$ & P06 & $14(7)$ \\
\hline Q-02 & $3(1.5)$ & Q-19 & $5(2.5)$ & P02 & $23(11.5)$ & P08 & $9(4.5)$ & P08 & $4(2)$ \\
\hline
\end{tabular}

\section{DISCUSSION}

University students faced physical restrictions and psychological stress due to social isolation and remote learning imposed during the COVID-19 pandemic which affected countries all over the world. Our study aimed to investigate awareness, the physical activity level, sleep quality, depression severity and life satisfaction of university students during the COVID-19 outbreak. The findings of the current study will hopefully contribute to the literature and improvement of public health in a time of pandemic in which individuals spend longer time at home, go through a multitude of emotional changes, the education model changed (elearning, online and distance education) and experience reduced physical activity.

Since the pandemic and the new normalization process, which has an impact all over the world, has not been experienced before, there is no measurement tool for the evaluation of this period. Our study makes a significant 
contribution to the literature with this aspect. With the semi-structured scale developed, university students' level of self awareness about physical activity level and sleep quality was revealed. In our study, some gender-based differences were observed in the responses of the students to the questions asked about the pandemic. Female students longer seating times than male students. On the other hand, female students said that they spend more time sitting and exercise less frequently. According to the study parameters evaluated, it was observed that female students were more depressed, less satisfied with their lives, had poor sleep quality and exercised less than male students. We think that this may be related to the fact that female students are more adversely affected by the pandemic.

Regular physical activity increases learning motivation and cognitive success. (Huéscar Hernández et al.,2020) In this context, the time allocated to physical activity is very important in order for e-learning, which comes into our lives with new normalization, to be effective the increased sitting time during e-learning with physical activity. However, looking at the results of the scale directed to the students, it is observed that sitting times increased, but their physical activity levels did not increase at the same rate.

The profound positive effects of exercise on immunity justify the current suggested physical activity during COVID-19. (Ranasinghe et al., 2020) In the other hand, direct influence on immunity maintenance to sleep. Circadian rhythm alterations by the COVID-19 pandemic process compromise the quality of sleep and, for that reason, the immune system (De Sousa Martins, E.,2020) Therefore, the awareness of university students about the physical, social and cognitive effects of pyhsical activity should be increased.

In the literature, a study conducted in China, revealed that fear and uncertainty caused by COVID-19 increased the level of depression (Wang et al., 2020). Studies have emphasized that maintaining the physical activity level by exercising on a regular basis in pandemic period is important for relaxation and coping with stress (Rastegar Kazerooni et al., 2020). At the same time, attention was drawn to the use of exercise as a coping method to protect both physical and psychological health ( Holmes et al., 2020). In our study, students who exercised in accordance with the literature found a lower level of depression.
This is an indication that students stayed away from depression by doing exercises which helped them to cope with stress.

According to the literature, sleep and circadian rhythm disturbances are also directly related to depression.(Batterham et al., 2020, Byrne et al., 2019, Franzen et al., 2017). Consistently, sleep and circadian rhythm were found to be disturbed in university students in our study, in correlation with increased depression levels. We think that this is associated with increased time at home, uncertainty, fear of illness and anxiety for the future. Therefore, we believe that it is essential to take measures to address physical and psychological effects associated with the uncertainty about the duration of social isolation in a time of pandemic and to raise awareness in the community towards increasing physical activity level of individuals.

Economic concerns are among the factors that can cause deterioration of mental health during the pandemic (Williams et al., 2020). The universe of our study consisted of all students of the physiotherapy and rehabilitation department. However, 4th grade students showed more interest and provided more feedback compared to other students. Increased levels of depression of students can be regarded as a reflection of their professional and economic concerns about the future. Therefore, the awareness of university students about the physical, social and cognitive effects of pyhsical activity should be increased. Studies on coping techniques with COVID-19 highlight the importance of home exercises. WHO recommends at least 150 minutes of exercise a week, preferably at a moderate- and high-intensity (Ferreira et al., 2018, WHO, 2010).

In our study, it was found that students who devoted more time to exercise during the pandemic preferred doing moderate- and high- intensity exercises. A regular exercise program is crucial for protecting physical and mental health. In this context, a personalized exercise program can be created by physiotherapists and individual can learn his or her exercises and continue under the supervision of the physiotherapist. We believe that this is very important to maintain public health.

Many studies conducted during the COVID-19 outbreak have shown that exercise also increases life satisfaction (Zhang et al., 2020). It has been demonstrated that increased exercise time during the day increases life satisfaction (Zhang et al., 
2020) In our study, when the exercise patterns, exercise awareness, exercise levels and life satisfaction of the students were examined, it was seen that life satisfaction increased as they devoted more time to exercise. Once again, this clearly indicates that long-term adherence to personalized exercise programs is important in these days when there are various restrictions due to COVID-19.

In the studies that are included the students, questionnaires that can be scored with Likert's scale are frequently preferred (Croasmun and Ostrom, 2011). In our study, the effects of the pandemic process were evaluated with the semi structure 5-Likert scale with non-standard instrument. In the direction of the answers given to the questions created with Likert scale in the Covid 19 process, it was observed that the sitting periods increased in the pandemic process. It was determined that the students have low intensity exercise habits at home and they want to exercise with their families is low. It has been determined that students who done exercise that preferred relaxation exercises. Uncertainty and anxiety caused by the pandemic process are thought to increase the want to relax. Also, relaxation exercises may be preferred because they contain less physical activity and cause less fatigue. The students stated that they learned new things in this process. It was thought that the curiosity and interest in the developing and changing world with increasing leisure time during the day would cause this.

Certain limitations of our study deserve acknowledgment. First, in our study, the all universe could not be reached due to the difficulties of students accessing the internet. Nevertheless, the physical activity and depression levels, sleep patterns and life satisfaction of the students before the Covid-19 process are unknown. The consistency between the answers given to Q2 (I spent more time sitting during the pandemic) and Q8 (I spent less time sitting during the pandemic.) in the questions we prepared in the awareness questionnaire important. In this context, the students agreed that the time spent sitting increased. On the other hand, the consistency of their answers to the Q6 (My physical activity level increased during the pandemic) and Q7 (The time I spent doing sports increased during the pandemic) are an important result for this study. It reveals student's awareness of their physical activity and exercise levels.
Looking at the overall of our study, it was observed that with Covid-19, student's physical activity levels and life satisfaction decreased, as well as increased depression severity and impaired circadian rhythms during this process, where education was frequently continued as online / distance education. Two of these nested parameters directional interaction also draws attention. Therefore, protection of physical and mental health could be provide by increased selfawareness. Increased self-awareness in the students, increasing physical activity levels and it related parameters sleep quality, depression severity and life satisfaction, will improve. The individual exercise programs support that increased self-awareness on students. Individual exercise programs will be especially importance social isolation continues and on the days when students continue their education by distance education / online.

\section{Conflicts of interest}

All authors have no conflicts of interest with respect to the data collected and procedures used within this study. Authors declare that they have no sponsor in the study design, collection, analysis, interpretation of data, writing of the manuscript, and decision to submit the manuscript for publication.

\section{REFERENCES}

Aysan, E., Karaköse, S., Zaybak, A. and İsmailoğlu, E.G. (2014). Sleep Quality Among Undregraduate Students and Influencing Factors. DEUHYO ED, 7(3),193-198.

Batterham, P.J., Christensen, H., Mackinnon, A.J., Gosling, J.A., Thorndike, F.P., Ritterband, L. M. and Griffiths, K.M. (2017). Trajectories of change and long-term outcomes in a randomised controlled trial of internet-based insomnia treatment to prevent depression. $B$ $J$ Psych Open, 3(5): 228-235. doi: 10.1192/bjpo.bp.117.005231

Bulut, C. and Kato, Y. (2020). Epidemiology of COVID-19. Turk J Med Sci, 50(SI-1): 563570. doi: 10.1101/2020.05.04.20090712

Byrne, E.M, Timmerman, A., Wray, N.R. and Agerbo, E. (2019). Sleep Disorders and Risk of Incident Depression: A Population CaseControl Study. Twin Research and Human Genetic,22(3):140-146.doi: 
10.1017/thg. 2019.22

Croasmun, J.T. and Ostrom, L. (2011). Using Likert-Type Scales in the Social Sciences. Journal of Adult Education, 40(1): 19-22.

De Sousa Martins, E., Ono, S.B.H.V.S., \& Souza, J. C. (2020). Sleep and immunity in times of COVID-19. REV ASSOC MED BRAS, 66(2), 143-147.

Ferreira, M.J., Irigoyen, M.C., Consolim Colombo, F., Saraiva, J.F.K and De Angelis, K. (2018). Physically Active Lifestyle as an Approach to Confronting COVID-19. Int J Environ Res Public Health, 15(5). doi: 10.36660/abc.20200235.

Fisher, J.J., Kaitelidou, D. and Samoutis, G. (2019). Happiness and physical activity levels of first year medical students studying in Cyprus: a cross-sectional survey. $B M C$ Med Educ, 19(1): 1-7. doi: 10.1186/s12909019-1790-9.

Franzen, P.L and Buysse, D.J. (2017). Sleep in psychiatric disorders. In Sleep disorders medicine, 977-996. doi: 10.1007/978-14939-6578-6_46.

Gossenheimer, A. N., Bem, T., Carneiro, M.L.F., $\&$ de Castro, M.S. (2017). Impact of distance education on academic performance in a pharmaceutical care course, PloS one,12(4).doi:10.1371/journal.pone.0175117

Holmes, E.A., Connor, R.C., Perry, V.H., Tracey, I., Wessely, S., Arseneault, L. and Ford, T. (2020). Multidisciplinary research priorities for the COVID-19 pandemic: a call for action for mental health science. The Lancet Psychiatry,7, 547-560. doi: 10.1016/S22150366(20)30168-1.

Huéscar Hernández, E., Andrés Fabra, J.A., \& Moreno Murcia, J.A. (2020). Effect of autonomy support and dialogic learning on school children's physical activity and sport. Scandinavian Journal of Psychology, 61(3), 402-409

İnal İnce, D., Vardar Yağlı, N., Sağlam, M., Çalık Kütükcü, E. (2020). Acute And Post-Acute Physiotherapy And Rehabilitation In Covid19. Turkish Journal of Physiotherapy and Rehabilitation, 31(1),81-93. Do1: 10.21653/Tjpr.718877

Jackson Koku, G.(2016). Beck depression inventory. Occupational Medicine, 66(2): 174-175. doi: 10.1093/occmed/kqv087

Kaya E Ö, Sarıtaş N, Yıldız K, Kaya M. (2018). A
Research On The Physical Activity And Life Satisfaction Levels of Sedantary and NonSedentary Individuals. Celal Bayar University Journal of Institute of Health Sciences; 5(3): 89-94

Lee, A. (2020). COVID-19 and the Advancement of Digital Physical Therapist Practice and Telehealth. Physical Therapy. doi: 10.1093/ptj/pzaa079

Lee, P.H., Macfarlane, D.J., Lam, T.H. and Stewart, S.M. (2011). Validity of the international physical activity questionnaire short form (IPAQ-SF): A systematic review. International Journal of Behavioral Nutrition and Physical Activity, 8(1): 115. doi: 10.1186/1479-5868-8-115

Lorenzo Seva, U., Calderon, C., Ferrando, P.J., Del Mar Munoz, M., Beato, C., Ghanem, I. and Jiménez Fonseca, P. (2019). Psychometric properties and factorial analysis of invariance of the Satisfaction with Life Scale (SWLS) in cancer patients. Quality of Life Research, 28(5): 1255-1264. doi: 10.1007/s11136-019-02106-y

Mollayeva, T., Thurairajah, P., Burton, K., Mollayeva, S., Shapiro, C.M. and Colantonio, A. (2016). The Pittsburgh sleep quality index as a screening tool for sleep dysfunction in clinical and non-clinical samples: A systematic review and metaanalysis. Sleep medicine reviews, 25: 52-73. doi: 10.1016/j.smrv.2015.01.009

Patel, N.K., Nivethitha, L., \& Mooventhan, A. (2018). Effect of a yoga based meditation technique on emotional regulation, selfcompassion and mindfulness in college students. Explore, 14(6), 443-447. doi: 10.1016/j.explore.2018.06.008

Rastegar Kazerooni, A., Amini, M., Tabari, P. and Moosavi, M. (2020). Peer mentoring for medical students during COVID-19 pandemic via a social media platform. Med Educ, 762-763.. doi: 10.1111/medu.14206

Ranasinghe, C., Ozemek, C., \& Arena, R. (2020). Exercise and well-being during COVID 19time to boost your immunity. Expert Review of Anti-infective Therapy, 1-6.

Şencan, İ., Kuzi, S. (2020). Global threat of COVID 19 andevacuation of thecitizens of differentcountries. Turk J Med Sci, 50(SI-1): 534-543. doi:10.3906/sag-2004-21 
Tunay, V.B. (2008). Physical Activity in Adults. Klasmat Matbaac1lik, Ankara.

Wang, J., Wang, J.X. and Yang, G.S. (2020). The Psychological Impact of COVID-19 on Chinese Individuals. Yonsei Medical Journal, 61(5): 438-440. doi: 10.3349/ymj.2020.61.5.438

Williams, S.N., Armitage, C.J., Tampe, T. and Dienes, K. (2020). Public perceptions and experiences of social distancing and social isolation during the COVID-19 pandemic: A UK-based focus group study. MedRxiv, doi: 10.1101/2020.04.10.20061267

World Health Organization (WHO) (2010). Global recommendations on physical activity for health. Geneva.

World Health Organization (WHO). (2020). Clinical management of severe acute respiratory infection (SARI) when COVID19 disease is suspected.

Zhang, S.X., Wang, Y., Rauch, A. and Wei, F. (2020). Unprecedented Disruptions of Lives and Work - A Survey of the Health, distress and life satisfaction of people in China one month into the COVID-19 outbreak. Psychiatry research doi: 10.2139/ssrn.3555216

Zhang, S.X., Wang, Y., Rauch, A., Wei F. (2020). Unprecedented disruption of lives and work: Health, distress and life satisfaction of working adults in China one month into the COVID-19 outbreak. Psychiatry research. doi: 10.1016/j.psychres.2020.112958

How to cite this article: Dinler, E., Badat, T., Kocamaz, D. and Yakut, Y. (2020). Evaluation of the Student's Self Awareness, Physical Activity, Sleep Quality, Depression and Life Satisfaction of University Students During The COVID-19. Int J Disabil Sports HealthSci;3(2):128-139. https://doi.org/10.33438/ijdshs.770346 